\section{Evolution of Eucaryotic Cells}

IT seems generally accepted that the eucaryotic cellular form (that is, cells with developed nuclei) has developed from procaryotic forms. Stanier ${ }^{1}$ suggested that this transition may have taken place in the blue-green algae, because these have the same photosynthetic mechanism as do other algae and higher plants.

It often seems to be taken for granted that the transition took place in such a way that one procaryotic cell has developed into a eucaryotic one. It may, however, be just as fruitful to discuss the possibility that one eucaryotic cell has evolved from a number of procaryotic cells, for example, that it originates from something like a coenocytic relationship (that is, a relationship in which the cells are brought into contact without intervening cell walls) between procaryotic cells.

Fig. 1 gives an outline of this idea. The first step would be the establishment of a coenocytic relationship between anaerobic procaryotes, most probably of a single species. The DNA from the individual cells must be expected to accumulate in the centre of the compound cell, and may also form concatenates. The success of the cell at this stage would depend to a large extent on how efficiently the DNA can be distributed to the daughter cells when the cell is dividing. One can imagine the development of a primitive mitotic mechanism, perhaps based on the same principles that apply to the distribution of DNA in connexion with the division of the procaryotic cells. The development of a nuclear membrane from the endoplasmatic reticulum would seem to be a logical next step, as the mitotic process develops further. The resulting cell would be an anaerobic eucaryote.

With oxygen in the atmosphere (presumably from photosynthetic blue-green algae), aerobic procaryotes must have developed. We can then assume that some of the anaerobic eucaryotes established an endocellular symbiotic relationship with aerobic procaryotes. Such a symbiosis would certainly give them an evolutionary advantage over the anaerobic forms. During further evolution, the aerobic partner must necessarily have lost a great part of its autonomy. On a molecular basis, the loss of autonomy must mean a loss of DNA. This DNA may have become incorporated into the nuclear DNA, giving the eucaryotic cell a still better control over its aerobic partner. The final step in this evolutionary process would be the development of mitochondria as we know them from eucaryotic cells today.

The aerobic eucaryotic cell produced in this way could enter a new symbiotic relationship, this time with bluegreen algae of a primitive kind. The symbiotic relation- ship with blue-green algae must have developed along the same lines as the previous relationship, so that the photosynthetic partner must have lost a great part of its autonomy and DNA, to appear as the chloroplasts we know from eucaryotic algae and higher plants today.

An evolutionary line such as is suggested here can hardly be proved, although DNA/RNA hybridization experiments between blue-green algae and the chloroplasts of other algae, perhaps primitive Rhodophyceae, might give some information. The evolutionary advantage of the development of a eucaryotic cell like the one indicated here would be that it contained more DNA. In the beginning this would probably only mean the same information repeated several times, but mutations could give the basis for more information.

A further logical conclusion is that the eucaryotic cell which developed would take its genetic material mainly from the procaryotic forms making up the coenocytic system. Such coenocytic systems may have developed a number of times, from different procaryotic forms. Present-day eucaryotic organisms do not necessarily, therefore, have to be developed from one original species. This might even explain some of the rather puzzling parallels that exist between groups of procaryotic and oucaryotic organisms.

JOSTEIN GOKSOYR

Institute for General Microbiology,

University of Bergen,

Bergen, Norw ay.

Received March 13, 1967.

${ }^{1}$ Stanier, R. Y., in The Bacteria (edit. by Gunsalus, I. C., and Stanier, R. Y.), 5,445 (London, 1964).

\section{PATHOLOGY}

\section{Normal Human Serum Fluoride Concentrations}

TAVES $^{1}$ has indicated that our method ${ }^{2}$ for estimation of serum fluoride content based on diffusion of hydrogen fluoride gives results which are about ten times too large, but our values ${ }^{3}$ of human plasma fluoride content, which he quotes, were not obtained by the diffusion method but by an entirely different procedure ${ }^{4}$ which requires ashing of the sample with magnesium oxide followed by separation of the fluoride by distillation from perchloric acid. The agreement of the results for fluoride analyses of urine, bovine plasma, dentine, liver and muscle obtained by the two procedures ${ }^{1}$, which are quite different in principle, furnishes mutual support of the reliability and accuracy of both methods. Nevertheless, we have carried out further

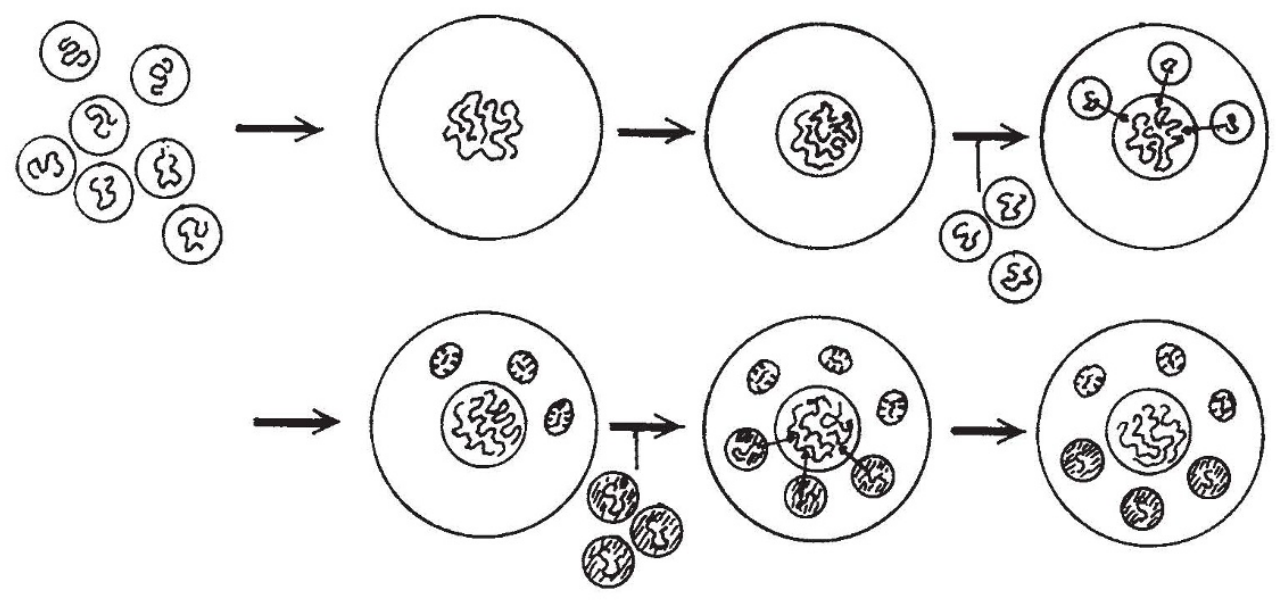

Fig. 1. Suggested evolutionary development of a eucaryotic photosynthetic cell from procaryotic forms. The small arrows within the cells indicate transfer of genetic material to the nucleus. See text for further details. 